\title{
AUTOMATIC TOOL MARK IDENTIFICATION AND COMPARISON WITH KNOWN BRONZE AGE HAND TOOL REPLICAS
}

\author{
Kristóf Kovács ${ }^{\mathrm{a}, \mathrm{b}, *}$, Klaus Hanke ${ }^{\mathrm{a}}$ \\ ${ }^{a}$ Institute of Basic Sciences in Civil Engineering, Surveying and Geoinformation Unit, University of Innsbruck, \\ Austria - (kristof.kovacs, klaus.hanke)@uibk.ac.at \\ ${ }^{\mathrm{b}}$ Institute of Geography, Georg-August-Universität Göttingen, Germany - kkovacs@gwdg.de
}

KEY WORDS: Tool Mark, Pattern Recognition, GIS, CAD, Structured Light Scanning, Bronze Age Replica

\begin{abstract}
:
The acquisition of high-resolution surface information by advanced documentation methods as short-range laser scanning or closerange photogrammetry can provide novel tool mark research perspectives in the field of archaeological sciences. For this reason, altogether eight different Bronze Age hand tool replicas and their tool marks were surveyed and analysed in this study. The automatic identification of sliding tool marks was carried out in a GIS environment. Based on hydrological and aspect parameters, the various hand tool impressions as watershed boundaries of the surface model could be determined in the developed workflow. After the segmentation of the single tool marks, slope and width values of the patterns were compared with the cutting edges of their replicas and the most used regions of the hand tool heads could be defined by these tool mark characteristics. The variation of midline parameters along the sliding tool marks resulted in significant conclusions about the mounting techniques of the hand tool heads on the handles. A smaller angular value between the replica and the handle produced different hand tool impressions which had a major influence on the woodworking efficiency as well. Furthermore, in this paper presented methods should also help to understand other ancient wood manufacture processes.
\end{abstract}

\section{INTRODUCTION}

The high-resolution and also budget-priced surveying methods offer several novel research opportunities in the field of archaeological sciences since the fine morphological characteristics of the finds can be analysed by such collected datasets.

For this reason, the investigation of the entirely preserved sliding tool marks on the surface of a Bronze Age sluice box could be accomplished during the last years within the HiMAT (History of Mining Activities in the Tyrol and Adjacent Areas Impact on Environment and Human Societies) project. These thirty-one wooden objects from Mitterberg, Austria were scanned with a spatial resolution of $0.2 \mathrm{~mm}$ and the post processing workflow for the tool mark recognition was established in Geographic Information System (GIS) environment (Kovács et al. 2012).

The evaluation of this advanced method was carried out after the documentation of various Bronze Age hand tool replicas and their test tool marks on a wooden object. The recent results of this tool mark-study are described in this paper.

The second section presents the motivation for this study and briefly reviews the related works in the field of tool mark recognition. The applied data acquisition techniques and the post processing method are discussed in the third section. After the automatic analysis of the test tool marks, the results of this workflow are presented in the fourth section. At the end of this paper, the conclusions and research perspectives are summarised.

\section{MOTIVATION AND RELATED WORKS}

The improvement of the pattern recognition studies can be observed in several disciplines such as in the Computer Vision (CV), environmental-, forensic- and archaeological sciences since the computer-based interpretation methods of the highresolution datasets are getting common due to the rapid developments of the sensors and the respective software. Therefore, the growing overlaps between these different disciplines can offer recent tool mark recognition opportunities as well. The micro-relief structures of an archaeological object are similar to the standard landform elements of the Earth such as valleys or mountain ridges, and for this reason, the GISbased surface analysis of the tool marks can provide significant interpretations for the archaeologists about the manufacturing process of the object (Kovács et al. 2011).

In 2009, forensic scientists have described in detail the main objectives of the tool mark-studies. These three criteria are the following: The specification of the individual characteristic number, which could offer a positive identification at the evidence investigation; the requirement of an exactly defined evaluation workflow and that the results of these exact studies must be repeatable as well (Committee on Identifying the Needs of the Forensic Sciences Community, National Research Council 2009). Based on these conditions, the aims of this tool mark-study can be summarized as "user-independent tool mark identification and implementation of automated methods for tool mark comparison and evaluation" (Kovács et al. 2012).

Photographic documentation was used to analyse the sliding tool marks on the wooden objects during an important archaeological research in the 1990's (Sands 1997). Due to the wide spreading of the high-resolution laser scanning survey instruments, the computer-based three-dimensional (3D)

\footnotetext{
* Corresponding author.
} 
investigations of the hand tool impressions could be arranged without any difficulty. After a similar data collection, the comparison of the wooden finds and their tool marks was achieved in digital environment within a more recent archaeological project (Lobb et al. 2010).

The visual evaluation of the tool marks and their signatures means a common method during the evidence investigation in the field of forensic science just like in the tool mark identification case of a mattock to a clod of soil (Clark 2011). However, the application of 3D digital microscope can provide exact signature comparison opportunities in the field of law enforcement (Shaw et al. 2011).

In the field of environmental researches, the basic concepts of the quantitative land-surface analysis have been defined in geomorphometry science (Hengl et al. 2008). Based on these ideas, an automatic classification workflow was carried out to map the standard landforms by pattern recognition principles (Jasiewicz et al. 2013).

In summary, the data acquisition of sliding tool marks can be established by various techniques from the traditional photographic documentation to the high-resolution laser scanning survey. On the one hand, the comparison of these hand tool impressions can be accomplished by user-dependent visual evaluations of tool mark signatures, but on the other hand, the computer-based comparison offers an objective interpretation method.

\section{DOCUMENTATION AND ANALYSIS METHODS}

\subsection{Structured Light Scanning of the Objects}

Altogether eight different Bronze Age hand tool replicas - two axes, three adzes and three chisels - were geometrically documented by a budget-priced structured light scanning (SLS) system within one working day (Figure 1). The volume of the cleaned dataset was in the order of 3.1 million points. The configuration during the data acquisition was the following: Around $50 \mathrm{~cm}$ distance between the objects and video projector; the achieved resolution of this setup was about $0.4 \mathrm{~mm}$.

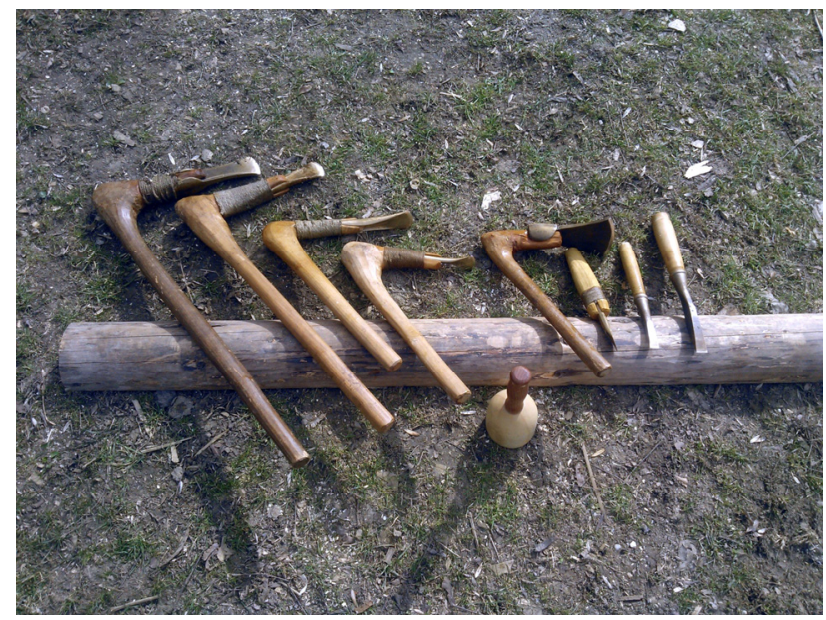

Figure 1. The selected eight different Bronze Age hand tool replicas; from left to right: two axes, three adzes and three chisels

The test tool marks were created by an experimental archaeologist on an approximately $60 \mathrm{~cm} \times 15 \mathrm{~cm} \times 10 \mathrm{~cm}$ wooden object at the Vienna Institute for Archaeological
Science (Figure 2). This object was scanned by the same hardware configuration of the SLS-system and resulted in a point cloud of 8.8 million points.

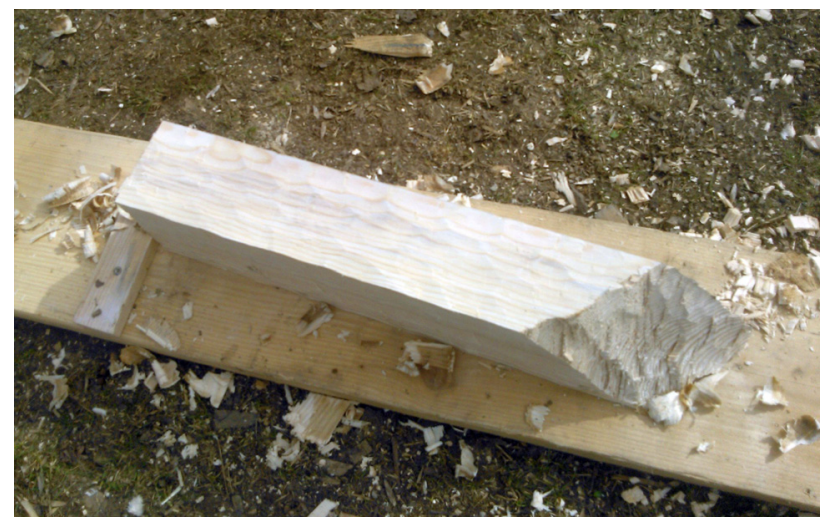

Figure 2. The investigated test tool marks

\subsection{Point Cloud Registration and the Export of XYZ Coordinates}

The first part of the post processing workflow was accomplished in the InnovMetric PolyWorks ${ }^{\circledR}$ Software. The overall thirty different point clouds of the wooden object with the hand tool impressions were registered in a joint coordinate system by "Best Fit Alignment" method. After this work step, the maximum residual between the overlapping areas was around $1 \mathrm{~mm}$.

Three different parts of this object was selected for further investigations. The test tool marks of the three adze replicas were created in these three regions and the merged point clouds of these areas were separately transformed in a basic coordinate system, where the XY coordinates are located in the horizontal plane and the $\mathrm{Z}$ coordinates present the vertical differences.

The tool mark recognition workflow was developed in a twoand-a-half-dimensional (2.5D) GIS environment. For this reason, the collected datasets could be analysed only after this accurate point cloud transformation.

\subsection{Automatic Tool Mark Recognition}

The idea of this identification concept is that the edge lines of the sliding tool marks can be interpreted as the boundaries of main "watersheds" and the smaller catchments within these sliding hand tool impressions can represent the facets, the single tool marks.

The basic overview of these work steps: After the raster interpolation of the imported XYZ coordinates, several hydrologic characteristics such as "Flow Accumulation" and "Flow Direction" parameters of the hand tool impressions were calculated in ArcGIS ${ }^{\circledR}$ Software. The pour points of the catchments were precisely defined by the combination of the calculated stream network and the boundaries between the main aspect classes of the surface model. Finally, the watersheds were identified by the "Flow Direction" characteristics and by the pour point positions (Figure 3).

The aspect calculations were used to help the identification process of the watershed pour points. In most cases, the edge lines of the sliding tool marks are running parallel on the object surfaces. For this reason, the direction of these edge lines implied the main categories during the definition of aspect classes. The boundaries of aspect changes between these main categories can represent the edges of hand tool impressions and 
after the intersections with the stream network, the locations of the pour points could be determined.

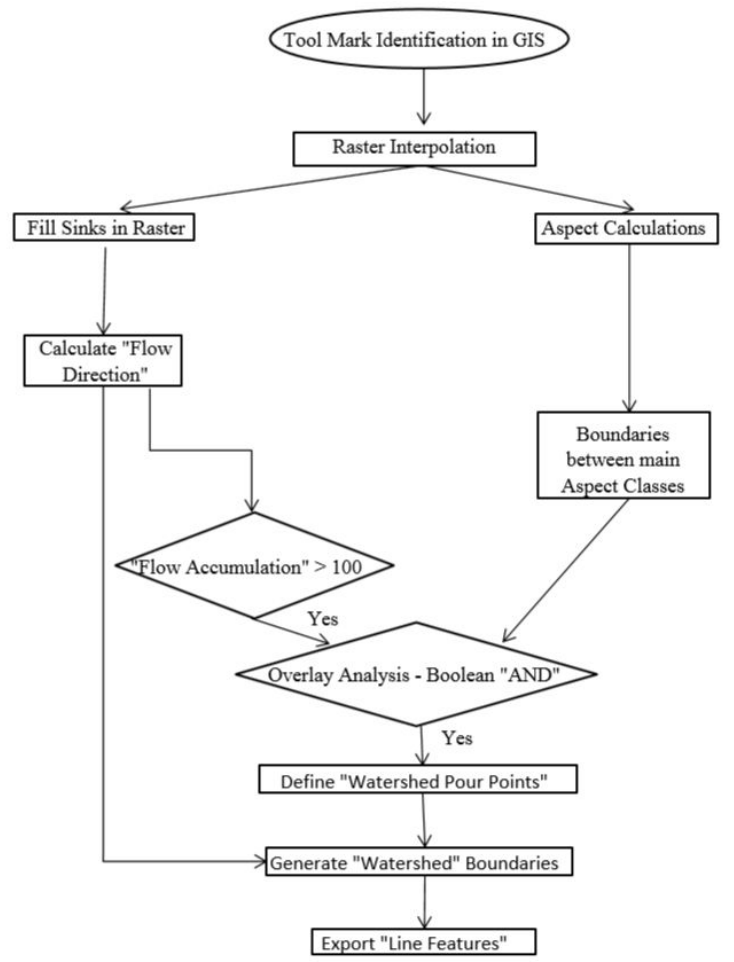

Figure 3. Flowchart of the automatic tool mark recognition in GIS

After this tool mark extraction process, altogether 103 objects were recognized within these three regions.

\subsection{Analysis of the Bronze Age Hand Tool Replicas}

The exact parameters of the heads of the selected three adze replicas could be also calculated after the SLS documentation. The shape of the adzes were analysed by basic measurement tools in a CAD system. Based on this SLS survey, the average slopes of the cutting edges were calculated by the angles between the horizontal lines and the both end points of these edges. Furthermore, the two of them were $41 \mathrm{~mm}$ and $46 \mathrm{~mm}$ width and the size of the third one was $104 \mathrm{~mm}$. During the experiment, the two $10 \mathrm{~cm}$ width sides of the wooden object were processed by the two smaller hand tools and the biggest replica was utilised to create the test tool marks along the one of the $15 \mathrm{~cm}$ width sides.

Approximately sixty per cent of the extracted watershed boundaries could be located at the side of this object. For this reason, overall thirty complete single tool marks from the three middle regions were used for further analysis.

\section{EVALUATION OF THE TEST TOOL MARKS}

\subsection{Comparison of the Calculated Width and Slope Values in GIS and CAD}

The computer-based investigation of these different hand tool impressions could be accomplished in GIS environment. At first, cross-sections were defined at $1 \mathrm{~mm}$ step along these thirty patterns. The average width and slope parameters of these polyline features could be determined by the interpolated surface model and these values were compared with the real parameters of the replicas (Table 1).

\begin{tabular}{|c|c|c|c|}
\hline & Hand Tool Nr.1 & Hand Tool Nr.2 & Hand Tool Nr.3 \\
\hline $\begin{array}{c}\text { Number of the } \\
\text { Investigated Test } \\
\text { Tool Marks }\end{array}$ & 10 & 10 & 10 \\
\hline $\begin{array}{c}\text { Width of the Replica } \\
\text { Heads }\end{array}$ & $41 \mathrm{~mm}$ & $46 \mathrm{~mm}$ & $104 \mathrm{~mm}$ \\
\hline $\begin{array}{c}\text { Average Width of } \\
\text { the Test Tool Marks }\end{array}$ & $18.9 \mathrm{~mm}$ & $22.3 \mathrm{~mm}$ & $40.4 \mathrm{~mm}$ \\
\hline $\begin{array}{c}\text { Average Slope along } \\
\text { the Replica Heads }\end{array}$ & $29.8 \%$ & $37.3 \%$ & $18.6 \%$ \\
\hline $\begin{array}{c}\text { Average Slope along } \\
\text { the Cross-Sections }\end{array}$ & $6.5 \%$ & $7.3 \%$ & $5.9 \%$ \\
\hline
\end{tabular}

Table 1. The evaluation of the width and slope values

After this step, the average width parameters of the test tool marks were applied to define a second slope value for the heads of the adzes. The polylines of the complete cutting edges were intersected by these calculated width parameters of the hand tool impressions and the new angles were determined between the horizontal lines and the both intersection points (Figure 4).

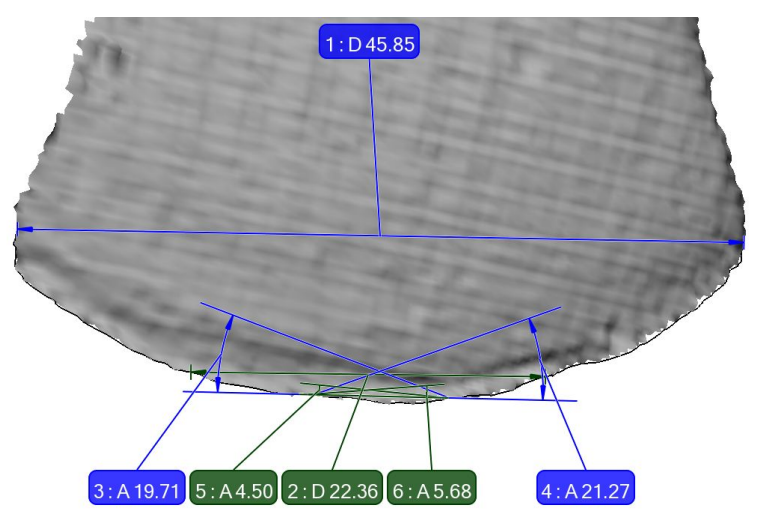

Figure 4. Hand Tool Nr.2 - CAD-based width and slope analysis of the cutting edge (distances in $\mathrm{mm}$, angles in degrees); the blue parameters are representing the complete shapes, the green values were created after average width calculations of their test tool marks

The results of the second slope values are the following: Hand Tool Nr.1: 7.5\%; Hand Tool Nr.2: 8.9\%; Hand Tool Nr.3: $4.2 \%$. Significant matching could be observed between these parameters and the average slopes of the cross-sections which helped to identify the most used regions of the cutting edges during this experiment.

\subsection{Comparison of the Tool Mark Midlines}

The midlines of the thirty tool marks could be automatically generated by the midpoints of the cross-sections in ArcGIS ${ }^{\circledR}$ Software. The results of this comparison are presented in the following table: 


\begin{tabular}{|c|c|c|c|}
\hline & Hand Tool Nr.1 & Hand Tool Nr.2 & Hand Tool Nr.3 \\
\hline $\begin{array}{c}\text { Number of the } \\
\text { Investigated Test } \\
\text { Tool Marks }\end{array}$ & 10 & 10 & 10 \\
\hline $\begin{array}{c}\text { Average Length of } \\
\text { the Test Tool Marks }\end{array}$ & $43.2 \mathrm{~mm}$ & $63.3 \mathrm{~mm}$ & $70.4 \mathrm{~mm}$ \\
\hline $\begin{array}{c}\text { Mean of the Highest } \\
\text { Slope Values along } \\
\text { the Midlines }\end{array}$ & $16.4 \%$ & $24.5 \%$ & $25.6 \%$ \\
\hline
\end{tabular}

Table 2. The evaluation of the tool mark midlines

The two smaller replicas have almost the same head shapes; however, the tool marks of the first adze are significantly shorter and the highest slope values along the midlines are also lower. After the investigation of the three adze handles, this issue could be explained in CAD environment (Figure 5). The angles between the heads and their handles were determined by extracted standard geometries and these results are the following: Hand Tool Nr.1: 49.3; Hand Tool Nr.2: 56.4 ; Hand Tool Nr.3: $54.9^{\circ}$.

In the case of the hand tool Nr.1, this smaller angle could produce a major influence on the characteristics of their tool marks since this adze's movements should have a different trajectory during the usage. The creation of much longer single tool marks by this adze would result smaller slope values along their midlines.

Furthermore, the depth and the length parameters of the sliding tool marks could be also visualised by these midpoints (Figure $6)$.

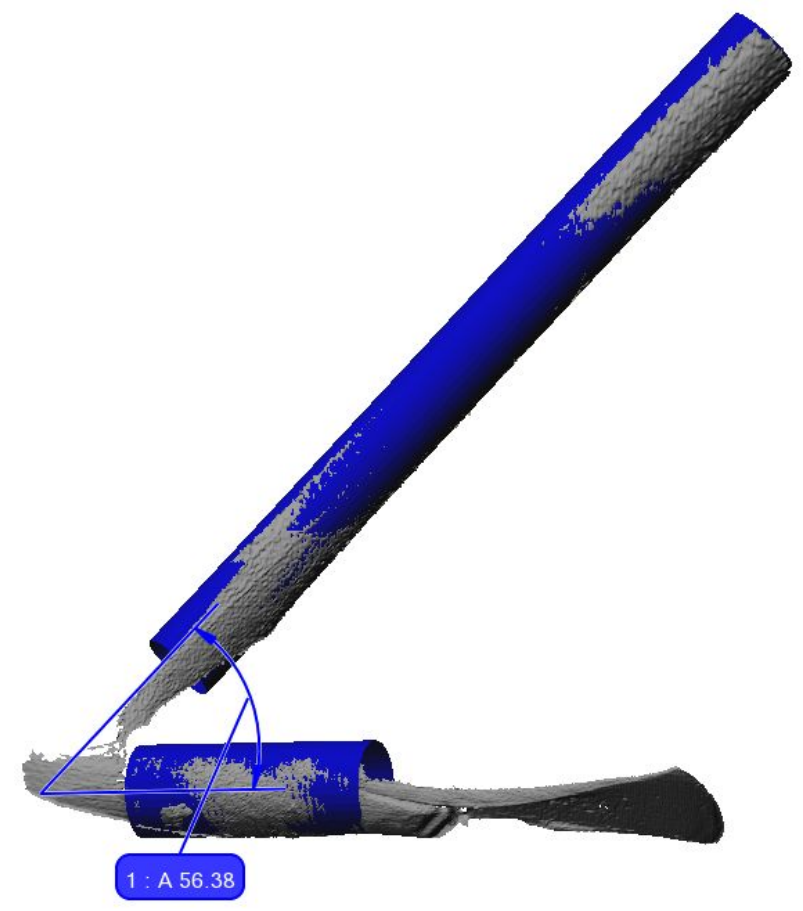

Figure 5. Hand Tool Nr.2 - The angle between the head and the adze handle (in degrees); the blue cylinders were created by "Best Fit" method and the axes of these cylinders were used during the angle calculations

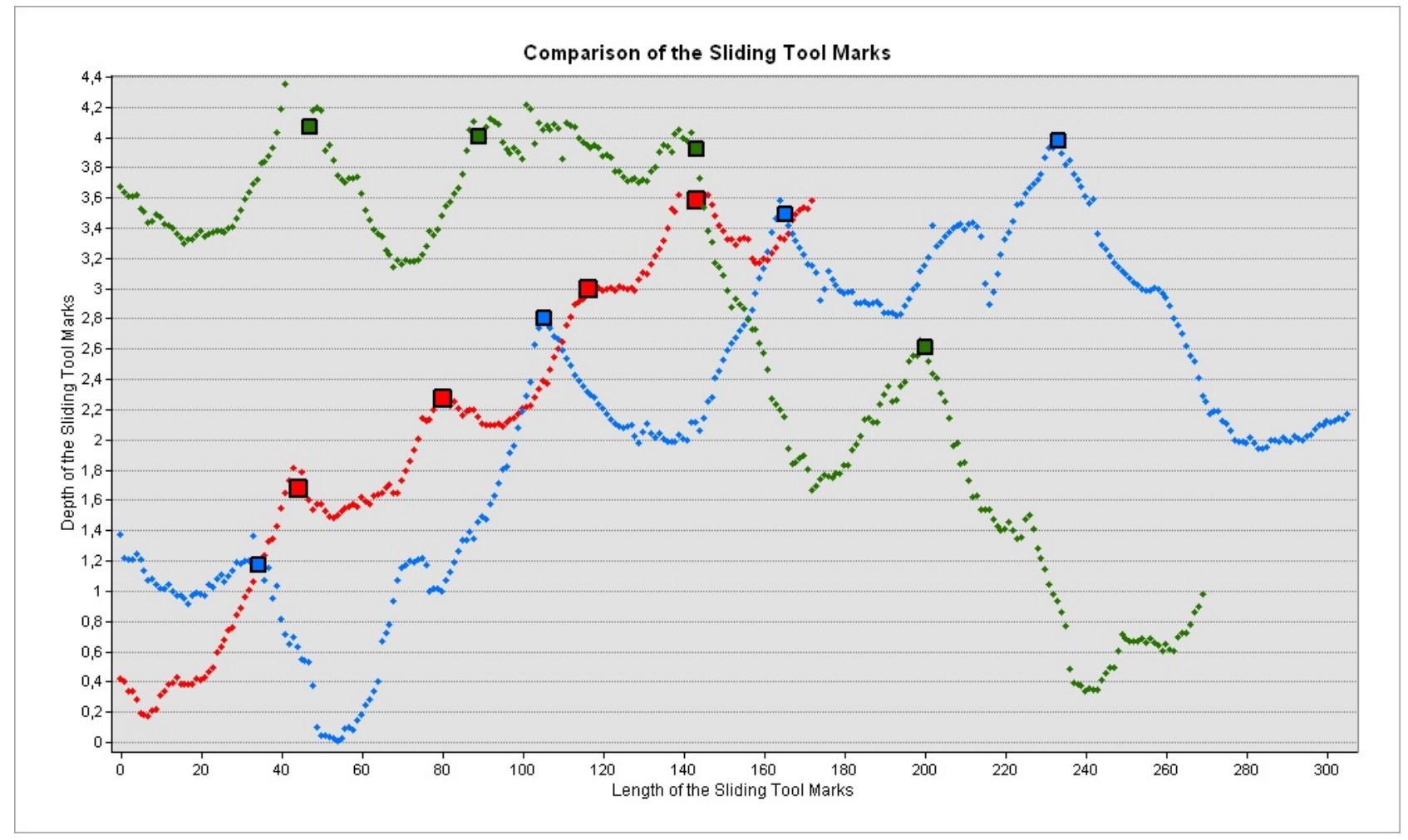

Figure 6. The long profiles of the sliding tool marks along the middle region of the wooden object (in mm) - red points: Hand Tool Nr.1; blue points: Hand Tool Nr.2; green points: Hand Tool Nr.3. The highlighted points represent the calculated watershed boundaries, the borders of the facets. 


\subsection{Investigation of the Area and Volume Characteristics}

The area and volume values of the thirty selected tool marks were also analysed in GIS environment since these volume parameters could be calculated by separately predefined polygons in "3D Analyst Tools" (Figure 7). These different polygon features were fitted at the highest point of the facets and the volumes between these features and the selected catchments were established in every thirty cases. The complete experiment was recorded with a digital video camera. For this reason, the exact working time during the processing of these three sides could be also measured.

After the combination of these components, two important basic parameters of these adzes could be estimated: The processed area and volume within $10 \mathrm{~s}$, achieved by an experimental archaeologist (Table 3). Several dissimilarities between the hand tool Nr.1 and the hand tool Nr.2 have been already described in the previous section. The various mounting techniques of the almost same adze heads can produce important differences in quantitative characteristics of the woodworking process. Compared to the hand tool Nr.2, approximately the $81 \%$ of the area and $60 \%$ of the volume can be achieved by the hand tool Nr.1 within the same working time. The lower slope values along the sliding tool marks of the hand tool Nr.1 could be also correlated with this smaller volume.

The mounting angles of the Nr.2 and Nr.3 adzes are identical. On the other hand, the cutting edge size is almost the double in the case of the hand tool Nr.3. Based on these facts, these estimated parameters of this biggest adze could be successful compared to the hand tool Nr.2.

\begin{tabular}{|c|c|c|c|}
\hline $\begin{array}{c}\text { Number of the Investigated } \\
\text { Test Tool Marks }\end{array}$ & 10 & 10 & 10 \\
\hline $\begin{array}{c}\text { Overall Area on the Three } \\
\text { Different Sides of the } \\
\text { Wooden Object }\end{array}$ & $42184 \mathrm{~mm}^{2}$ & $55600 \mathrm{~mm}^{2}$ & $71711 \mathrm{~mm}^{2}$ \\
\hline $\begin{array}{c}\text { Overall Area of the } \\
\text { Investigated Test Tool } \\
\text { Marks within these Regions }\end{array}$ & $7863 \mathrm{~mm}^{2}$ & $13222 \mathrm{~mm}^{2}$ & $22907 \mathrm{~mm}^{2}$ \\
\hline $\begin{array}{c}\text { Percentage of the } \\
\text { Investigated Test Tool } \\
\text { Marks }\end{array}$ & $19 \%$ & $24 \%$ & $32 \%$ \\
\hline $\begin{array}{c}\text { Overall Volume of the } \\
\text { Investigated Test Tool } \\
\text { Marks }\end{array}$ & $8641 \mathrm{~mm}^{3}$ & $19692 \mathrm{~mm}^{3}$ & $36632 \mathrm{~mm}^{3}$ \\
\hline $\begin{array}{c}\text { Working Time - Complete } \\
\text { Side }\end{array}$ & $156 \mathrm{~s}$ & $171 \mathrm{~s}$ & $106 \mathrm{~s}$ \\
\hline $\begin{array}{c}\text { Working Time - Test Tool } \\
\text { Marks }\end{array}$ & $30 \mathrm{~s}$ & $41 \mathrm{~s}$ & $34 \mathrm{~s}$ \\
\hline Processed Area within 10s & $2621 \mathrm{~mm}^{2}$ & $3225 \mathrm{~mm}^{2}$ & $6737 \mathrm{~mm}^{2}$ \\
\hline $\begin{array}{c}\text { Processed Volume within } \\
\text { 10s }\end{array}$ & $2880 \mathrm{~mm}^{3}$ & $4803 \mathrm{~mm}^{3}$ & $10774 \mathrm{~mm}^{3}$ \\
\hline
\end{tabular}

Table 3. The evaluation of the tool mark area and volume characteristics - yellow table rows: calculated values in GIS; green table row: measured time; blue table rows: estimated parameters by the known factors

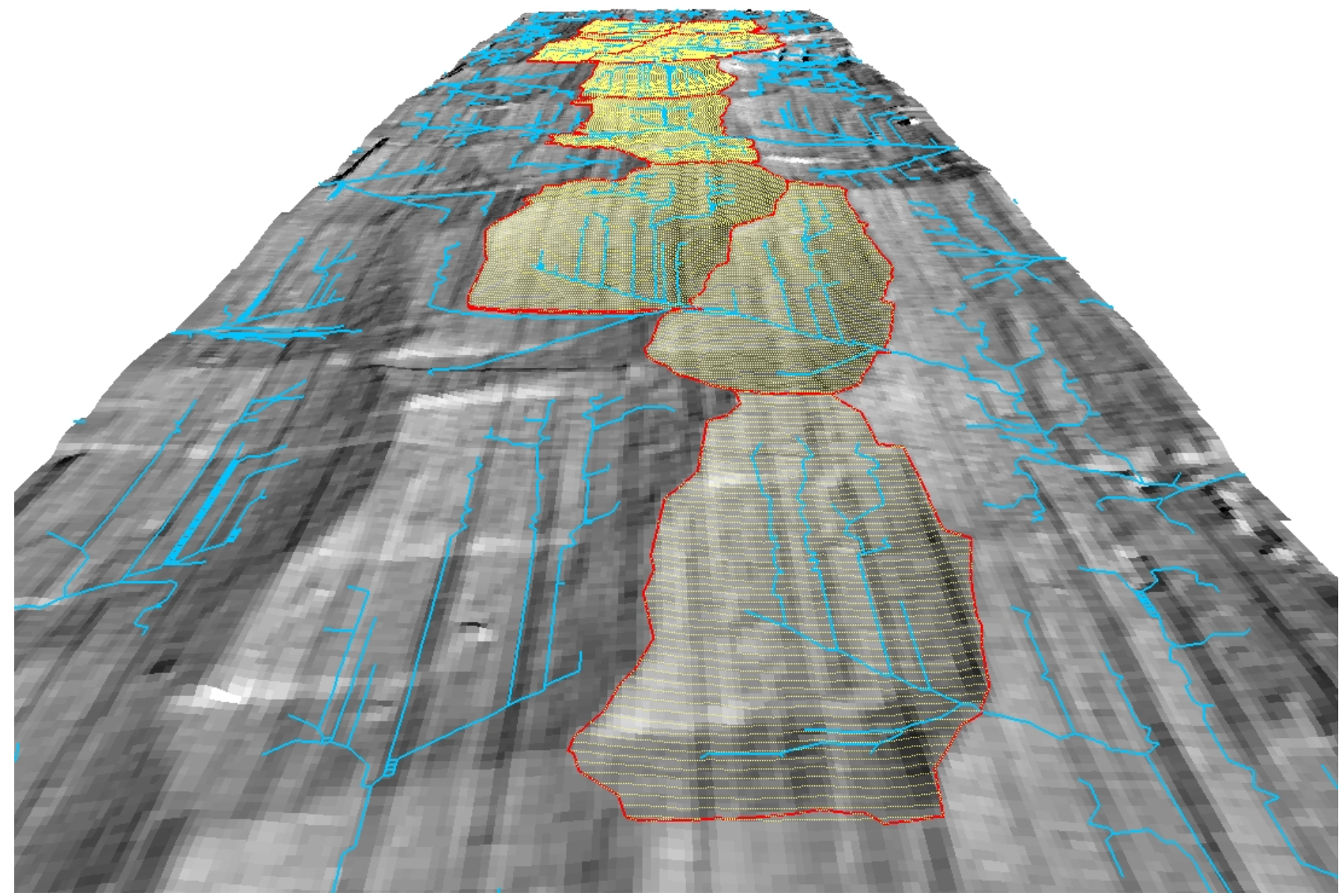

Figure 7. Hand Tool Nr.2 - Visualisation of the selected tool marks in 3D GIS environment - blue lines: calculated stream network; red lines: the facets, the boundaries of the predefined polygons; yellow lines: the extracted cross-sections 


\section{CONCLUSIONS AND FUTURE WORK}

This GIS-based tool mark recognition and evaluation workflow offers novel research opportunities in the field of archaeological sciences. After the automatic segmentation of the hand tool impressions, the evaluation of the selected tool marks and their replicas has produced significant conclusions about the Bronze Age woodworking process since the various mounting techniques of the adze heads have resulted different tool mark characteristics. Furthermore, these area and volume dissimilarities could be correlated with the size of the cutting edges as well.

This documentation of the working time should help to calculate standard factors for other ancient wood construction processes. In the future, these invented methodologies must be combined with other known parameters as the documented adze strike numbers. Based on these test tool marks, the recognition of the woodworking directions and the trajectories of the hand tool movements should be also investigated.

\section{ACKNOWLEDGMENT}

The work is generously supported by the Austrian Science Fund (FWF Project F3114) in the framework of the Special Research Program "History of Mining Activities in the Tyrol and Adjacent Areas" (SFB HiMAT) as well as by the Austrian province governments of Tyrol, Vorarlberg and Salzburg, the Autonomous Province Bozen-South Tyrol, Italy, the local authorities of the mining areas concerned, the TransIDEE foundation and the University of Innsbruck, Austria.

Special thanks to Wolfgang Lobisser, Vienna Institute for Archaeological Science, for his support during the scientific experiment.

\section{REFERENCES}

Clark, M. D., 2011. Toolmark Identification of a Mattock to a Clod of Soil from a Grave. Journal of Forensic Sciences, Vol. 56, No. 1.

Committee on Identifying the Needs of the Forensic Sciences Community, National Research Council., 2009. Strengthening Forensic Science in the United States: A Path Forward. National Academies Press.

Hengl, T., Reuter, H.I., 2008. Geomorphometry: Concepts, Software, Applications. Elsevier Science, ISBN 9780123743459, pp. 3-6.

Jasiewicz, J., Stepinski, T.F., 2013. Geomorphons - a pattern recognition approach to classification and mapping of lanforms. Geomorphology Vol. 182, pp. 147-156.

Kovács, K., Hanke, K., Moser, M., 2011. GIS-based surface analysis of archaeological finds. Proceedings of the ISPRS Workshop '3D-ARCH 2011'"3D Virtual Reconstruction and Visualization of Complex Architectures" In: The International Archives of Photogrammetry, Remote Sensing and Spatial Information Sciences, Vol. XXXVIII-5/W16.
Kovács, K., Hanke, K., 2012. Hydrologic and feature-based surface analysis for tool mark investigation on archaeological finds, In: The International Archives of Photogrammetry, Remote Sensing and Spatial Information Sciences, XXXIX-B5, pp. 565-570.

Lobb, M., Krawiec, K., Howard, A. J., Gearey, B. R., Chapman, H. P., 2010. A new approach to recording and monitoring wet-preserved archaeological wood using threedimensional laser scanning. Journal of Archaeological Science, Vol. 37, Issue 12, pp. 2995-2999.

Sands, R., 1997. Prehistoric Woodworking: The analysis and interpretation of Bronze and Iron Age toolmarks. University College London: Archetype Press.

Shaw, Kai-Ping., Chung, Ju-Hui., Chung, Fang-Chun., Tseng, Bo-Yuan., Pan, Chih-Hsin., Yang, Kai-Ting., Yang, ChunPang., 2011. A Method for Studying Knife Tool Marks on Bone. Journal of Forensic Sciences, Vol. 56, No. 4. 